\title{
Deciphering Alzheimer Disease
}

\author{
Dennis Selkoe ${ }^{1}$, Eckhard Mandelkow ${ }^{2}$, and David Holtzman ${ }^{3}$ \\ ${ }^{1}$ Center for Neurologic Diseases, Harvard Medical School and Brigham and Women's Hospital, Boston, \\ Massachusetts 02115 \\ ${ }^{2}$ Max-Planck Unit for Structural Molecular Biology, Hamburg 22607, Germany; and DZNE, German \\ Center for Neurodegenerative Diseases, and CAESAR Research Center, 53175 Bonn, Germany \\ ${ }^{3}$ Department of Neurology, Washington University School of Medicine, St. Louis, Missouri 63110 \\ Correspondence: dselkoe@rics.bwh.harvard.edu
}

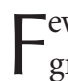
ew diagnoses in modern medicine evoke greater apprehension and sadness than Alzheimer disease. Virtually unknown to the public just a generation ago, this protean disorder is now the subject of enormous concern on a personal level and represents a looming catastrophe for society. Most people in developed nations have encountered victims of the disease, often within their own families, and there is a palpable sense of urgency that something be done. Yet patients told that they have Alzheimer disease quickly learn that no proven disease-modifying treatment exists and that they are destined to experience the insidious loss of their most human qualities - memory, reasoning, abstraction, language, and emotional stability. Now, based on the power of reductionist biology, this bleak situation appears poised to change.

Breathtaking advances in our fundamental knowledge of molecular biology and cellular function during the last half-century have provided a platform on which thousands of scientists worldwide are building an understanding of how Alzheimer disease works. Like other new scientific subjects, research on Alzheimer disease has experienced its share of controversy and confusion. However, there are far more advances than setbacks, and many within the field believe that a rough consensus about how the disorder begins and evolves has emerged. The articles in the CSH Perspectives in Medicine subject collection on The Biology of Alzheimer
Disease explore in depth many aspects of this complex syndrome and explain how molecular understanding is leading to novel therapeutic agents that may one day also be used to prevent the disorder.

\section{THE MELDING OF BASIC AND APPLIED BIOLOGICAL RESEARCH}

Most of us interested in science have grown up with the paradigm that there are two broad areas of scientific effort: "basic" and "applied.” In biology, it is understood that many programs of experimentation seek to uncover the fundamental rules by which molecules are created, interact, and give rise to cellular and organismal function. On the other hand, there is great interest in pursuing a wide range of clues about how specific diseases begin, progress, and may ultimately be thwarted. However, in the last few decades, scientists have increasingly recognized that this paradigm constitutes an inaccurate dichotomy. Many investigators whose careers have focused on normal physiology are interested in the implications of their findings for the mechanisms of unsolved diseases. In turn, those who have intensively studied human disorders and cellular and animal models thereof have sometimes contributed novel and powerful insights into the normal functions of molecular and cellular systems. This blurring of the classical boundaries is not surprising and, indeed, is highly salutary for

Editors: Dennis J. Selkoe, Eckhard Mandelkow, and David M. Holtzman

Additional Perspectives on The Biology of Alzheimer Disease available at www.perspectivesinmedicine.org

Copyright (C) 2012 Cold Spring Harbor Laboratory Press; all rights reserved; doi: 10.1101/cshperspect.a011460

Cite this article as Cold Spring Harb Perspect Med 2012;2:a011460 
D. Selkoe et al.

both aspects of biological research. Scientists principally viewed as disease-oriented should strongly support more investment in so-called fundamental research, on which understanding of disease must be based, and traditionally "basic" scientists should be encouraged to extend their knowledge and methods directly into the mechanisms of the disorders that implicate the systems they are studying.

Research on the origins of Alzheimer disease and other age-related neurodegenerative disorders exemplifies this melding process. There is now an impressive list of genes and proteins, understanding of which emerged solely from an interest in Alzheimer disease. The amyloid $\beta$-protein precursor (APP), its homologous family members APLP-1 and APLP-2, the presenilins, and the $\beta$-secretases were all cloned within programs focused on elucidating Alzheimer disease. The discovery of presenilin (named after its role in the disease) as the first known intramembrane aspartyl protease and its function as a key signaling hub that processes many diverse receptors in multicellular organisms represents a signal contribution of Alzheimer research to protein biology. The recognition from studies of neurodegenerative diseases that certain neuronal proteins (e.g., tau, $\alpha$-synuclein) that are normally soluble may undergo alternative folding and oligomerize to gain new functional properties has helped illustrate the inextricable relationship between normal and abnormal protein folding. These and numerous other examples in the field of human neurodegeneration underscore the relevance of disease-oriented research to normal biology. This recognition gives added excitement and urgency to delving ever deeper into the mechanisms of disease.

\section{ALZHEIMER DISEASE AS A PROTOTYPE FOR THE MOLECULAR ELUCIDATION OF A COMPLEX, CHRONIC DISORDER OF THE HUMAN BRAIN}

Not very long ago, disorders like Alzheimer, Parkinson, and Huntington diseases were often assigned to the backs of textbooks of medicine as mechanistically obscure and therapeutically intractable syndromes. However, advances in two areas, biochemical pathology and human genetics, have dramatically changed this situation over just two decades. For the first 60 years after the Bavarian psychiatrist Alois Alzheimer described his index patient in 1907 (Alzheimer 1907), virtually no progress in our understanding of the causes and mechanisms of the disorder occurred. Then, the seminal papers on the electron microscopy of Alzheimer cytopathology by Robert Terry and Michael Kidd in the mid-1960s piqued an upswing in scientific interest (Terry 1963; Kidd 1964). In 1968, Gary Blessed, Bernard Tomlinson, and Martin Roth published a key clinicopathological study that confirmed what some neuropathologists had long suspected: the neuropathology of many cases of common senile dementia was indistinguishable from that of Alzheimer disease (Blessed et al. 1968). The latter disorder had first been described in a woman who died at age 56 and had been thought of as a distinct "presenile" dementia. However, the 1968 study supported the concept that Alzheimer disease occurred along an age continuum, with relatively rare cases appearing before the $60 \mathrm{~s}$ and the incidence rising steadily through the seventh to ninth decades and beyond.

This recognition of the shared neuropathological phenotype of cases regardless of age of onset soon led to a widespread awareness that Alzheimer disease, rather than being a rare presenile dementia, was a very common disorder. In 1976, Robert Katzman wrote a brief but influential piece that called attention to this fact and warned about an impending "epidemic" of cases as longevity rose in developed countries (Katzman 1976). In 1979, Jerome Stone and other lay Americans with affected family members organized the Alzheimer Association, headquartered in Chicago. This provided an enormous boost to public recognition of the disease and the personal and societal tragedy it represents. In the area of biochemical pathology, George Glenner first isolated and partially characterized the amyloid $\beta$-protein from the brains of patients who had died with Alzheimer disease or Down syndrome in 1984 (Glenner and Wong 1984a, b), and within two years, several 
laboratories had identified the microtubuleassociated protein, tau, as the principal constituent of the neurofibrillary tangles (Brion et al. 1985; Grundke-Iqbal et al. 1986; Kosik et al. 1986; Nukina and Ihara 1986; Wood et al. 1986). The cloning of the amyloid $\beta$-protein precursor in 1987 and discoveries of its diseasecausing mutations in 1990 and 1991 brought the field squarely into the era of molecular genetics and protein chemistry (Kang et al. 1987; Levy et al. 1990; Goate et al. 1991).

In this brief and incomplete overview of the emergence of modern Alzheimer research, one can sense the crescendo of public and scientific interest in the disorder. Today, hundreds of laboratories and clinics worldwide are intensely focused on applying many different approaches and techniques to characterize the Alzheimer phenotype at all levels and to search for opportunities to intervene. The array of observations, some seemingly contradictory, is daunting; it has become an enormous challenge to synthesize available findings into an accurate schema of how the disease starts, unfolds, and gradually devastates cognition, leading to the patient's premature death. In this collection, some of the leading clinical and laboratory scientists who have contributed importantly to our emerging understanding of pathogenesis and treatment have come together to share their knowledge and perspectives. They represent a much larger global community of students of Alzheimer disease. Assuming that the rate of progress continues to accelerate, Alzheimer disease may become a salient example of the steady move from phenomenology to detailed molecular understanding in a disorder of the most advanced biological system we know, the human brain.

\section{THE DRIVING FORCES THAT HAVE STIMULATED AD RESEARCH}

\section{The Quest for Scientific Clarity}

As in all fields of scientific inquiry, by far the strongest force for progress on Alzheimer disease derives from the innate curiosity of the individuals who have chosen to study the topic.
Attempting to contribute to the unraveling of this very complicated riddle provides enormous stimulation to the intellect. We often find ourselves in the laboratory or the clinic at times when our friends and families expect us to put aside our work. The complexity of the problem and the diverse ways in which one might think about approaching it make for a fascinating adventure in biomedical research. In one sense, this may be surprising to colleagues in other medical fields, as Alzheimer disease and other brain degenerations have long been viewed with intense therapeutic nihilism. Why would one have wished to focus one's work on this (until recently) obscure and enigmatic syndrome?

One motivation arises from the fact that Alzheimer disease represents at its onset a remarkably pure and insidious impairment of intellect. To those who entered neuroscience because of a fascination with the mind-brain relationship, deciphering the origins of this syndrome provides a window into the anatomic and molecular substrates of clear, well-organized thinking and the subtle events that can perturb memory and reasoning. Inspired by the towering examples of nineteenth-century neuroscientists like Broca, Charcot, and Sherrington, who used neural deficits to elucidate normal nervous system function, investigators hope to help validate some of the emerging rules of normal memory and cognitive function by understanding which circuits and signaling pathways explain the earliest symptoms of Alzheimer disease. This relationship is illustrated not only by the molecular dissection of the disease in the laboratory but also by clinical approaches such as functional magnetic resonance imaging, in which one can examine in vivo the brain networks that become activated in abnormal ways when subjects destined to develop Alzheimer disease years later attempt to remember specific patterns such as facename pairs.

In the last two decades, it has become apparent that Alzheimer disease involves changes in many overlapping molecular, cellular, and anatomical pathways. Students of the disease may choose to focus their work on neuropathology, protein folding, substrate-protease biochemistry, 
D. Selkoe et al.

synaptic structure and function, signal transduction, cytoskeletal biology, inflammation, oxidative metabolism, neurotransmitter pharmacology, metal ion homeostasis, or behavioral phenotyping in murine models. In short, $\mathrm{Alz}$ heimer research touches upon virtually the entire range of biological inquiry. The breadth and heterogeneity of the field is evidenced by a bewildering array of findings, many seemingly unrelated, that appear in innumerable publications each month. Investigators generally tend to focus on a topic that is familiar to them and produce data that are often heralded as a critical insight into the mechanism of the disease. This experimental ferment provides intellectual stimulation but can also lead to confusion and controversy, with seemingly important observations not easily confirmed by other laboratories. Nevertheless, there has been a steady movement over the years toward mechanistic consensus, as discussed in this collection.

\section{The Personal Tragedy of Alzheimer Disease}

For many who contribute to this field, a prime motivator for their work is a painful awareness of how Alzheimer disease and similar progressive dementias devastate the lives of victims and their families. Among chronic diseases, Alzheimer is particularly poignant in that it erodes the patient's intellectual and emotional life and often destroys the rewards of retirement that individuals have longingly anticipated throughout their working lives. There are few more painful experiences than to see a beloved parent or sibling slowly but inexorably become a person one can hardly recognize. In this sense, Alzheimer disease compounds its suffering by exacting enormous pressure and dislocation on the family of the victim.

An advantage of studying a highly prevalent disorder is that even those scientists who otherwise would have little occasion to witness the clinical syndrome first-hand are acquainted with patients harboring the disorder. The majority of researchers focused on Alzheimer disease globally are not clinicians caring for patients. However, the frequent linkage of these scientists to centers of clinical expertise, coupled with active dissemination through professional and lay fora of what the Alzheimer phenotype is like, enables students of the problem at all levels to have an understanding of its clinical development and consequences. Those who interact professionally with patients and their loved ones and watch the disease unfold have a strong additional motivation for working on the problem beyond its scientific fascination. However, one does not need to be involved in patient care to feel the enormous desire to help these individuals. All of us engaged in this endeavor are inspired to contribute in ways large and small to the relief of suffering and, ultimately, to the prevention of this most common late-life dementia.

\section{The Societal Crisis of Alzheimer Disease}

As if the patient's personal burden were not sufficient motivation, the enormous public health impact of the rising prevalence of Alzheimer disease further focuses one's attention. Projections of the combined economic burden of medical care and lost productivity vary widely, but all of the estimates are alarmingly high. It is believed that the number of patients diagnosed with Alzheimer disease worldwide may rise from the current approximation of 20-25 million to perhaps three times that number by mid-century, assuming no meaningful diseasemodifying intervention occurs. The scientific progress reviewed in this collection makes that outcome increasingly unlikely, but many more cases will accrue before even optimistic predictions of early treatment and prevention show an impact on prevalence.

In the United States, the message that Alzheimer disease is a public health emergency has been brought forward most effectively by two entities: the National Institute on Aging (NIA) and the Alzheimer Association. Since its founding in 1974, the NIA has expended enormous effort to bring a message of urgency to both the scientific and lay communities. Among the several National Institutes of Health institutes that help fund aspects of Alzheimer research, the NIA serves as the principal funder of laboratory and clinical research nationally, 
and it has sponsored countless initiatives, symposia, workshops, and calls to action that have dramatically moved the effort forward. Many investigators have been trained, nurtured, and enabled by the NIA's scientific leadership over almost four decades.

Another major breakthrough in the quest to defeat the disease came from the efforts of a few affected families around 1979-1980 to organize the lay public into a focused and effective force for raising public awareness, helping suffering patients in many ways, and gathering precious funds for research. The success of the Alzheimer Association, which now sponsors the largest and most impactful international scientific meetings on the disorder, cannot be overestimated. Indeed, the example of American families organizing in this way has spawned not only chapters in all of the states and many local communities, but also sister organizations in countries throughout the world. The NIA and the Alzheimer Association often work together to move the field forward, and the scientific community is deeply indebted to their unceasing efforts on behalf of the cause.

\section{The Competition of Ideas and Findings: A Brief Perspective on "BAPtists versus TAUists"}

To those working within the field and perhaps also to many outside of it, Alzheimer research has sometimes been viewed as unusually contentious. However, a measured examination of the trajectory of the field over the past three decades suggests that controversy arose in large part out of the newness of the topic and the initial need to focus on poorly defined phenomena of the phenotype: the imprecision of the concept of "senile dementia" and the presence of brains lesions (senile plaques and neurofibrillary tangles) that occurred in highly variable densities and patterns within the Alzheimer brain but also in seemingly unrelated disorders. The era of rigorous biological analysis of the disease arguably began in the 1960s and 1970s. In those early days, investigators started to apply electron microscopy, biochemistry, and immunohistochemistry in attempts to uncover the nature of the classical morphological lesions and their local consequences. A growing focus on plaques and tangles as important phenomena of the disease was greeted with substantial skepticism, the argument being that the lesions Alzheimer described might well represent tombstones of a decades-long process and offer little insight into etiology.

Tissue deposits of amyloid, in particular, were well known to occur in certain systemic disorders of diverse cause, where they could arise as secondary reactions to more specific pathogenic events. The idea of "secondary amyloidosis" occurring in some hosts experiencing infectious, metabolic, or inflammatory disorders implied to some that the amyloid in Alzheimer disease might be an end-stage reaction with little pathogenic importance, the detritus of the process. This is a concern that is still voiced by some in the field, although the application of unbiased genetic approaches to familial Alzheimer disease has provided unequivocal evidence that at least some cases of the disorder are directly caused by dyshomeostasis of amyloid $\beta$-protein. Nonetheless, it remains a topic of debate as to whether these rare cases are closely related mechanistically to common "idiopathic" cases of Alzheimer disease. Because the two major lesions are composed of distinct proteins, tau in the case of the neurofibrillary tangles and amyloid $\beta$-protein in the case of amyloid plaques, the amusing aphorism that Alzheimer research is a kind of religious war between "BAPtists" and "TAUists" has even reached the lay public. However, the last few years have witnessed a palpable decrease in this tension, as inherited mutations in the APP or tau genes, mouse modeling of these genotypes, and careful analyses of the Alzheimer phenotype of Down syndrome have combined to clarify the order in which the two lesions arise in the disease. Several lines of evidence, all of which are reviewed in this collection, suggest that the cerebral accumulation of amyloid $\beta$-protein precedes and helps drive the deposition of the tau protein in neuronal perikarya and their processes. This recognition does nothing to diminish the pathogenic importance of tau alteration and 
D. Selkoe et al.

cytoskeletal impairment in Alzheimer disease. Indeed, recent studies suggest that the presence of the tau protein is necessary for expression of the downstream effects of amyloid $\beta$-protein on neurons.

Although it is interesting to attempt to assemble the myriad findings about the disease into a hypothetical sequence, one must bear in mind that dynamic information about the development of the process in Alzheimer patients themselves has been difficult to acquire. Almost certainly, many molecular and cellular changes occur virtually simultaneously and involve complex feedback loops, so that the evolution of the disorder is likely to be far less linear than current schemes propose. Nevertheless, the temporal ordering of events based on the latest available evidence can provide heuristic arguments for debate and pathogenic hypotheses that can be tested in animal models and later in human therapeutic trials. The rapid growth in fluid and imaging biomarker studies is particularly relevant to underpinning-or denying - the proposed cascades of pathogenesis.

\section{THE KEY SCIENTIFIC QUESTIONS TO BE ADDRESSED IN THIS COLLECTION: CAUSES, MECHANISMS, EFFECTS, AND THERAPIES}

Because laboratory and clinical research on Alzheimer disease over the past four decades has involved so many approaches and findings, an attempt to incorporate these into one comprehensive text is an exercise marked by a degree of hubris. It is impossible to capture all of the complex observations and competing ideas that mark this field of inquiry. Nevertheless, the editors and authors of this collection have attempted to cover the vast majority of the principal scientific topics that the $\mathrm{Al}$ zheimer research community concerns itself with today.

We begin with five articles that cover the clinical, neuropsychological, neuropathological, imaging, and biomarker phenotypes of the disease (Blennow et al. 2011; Johnson et al. 2011; Serrano-Pozo et al. 2011; Tarweh and Holtzman et al. 2011; Weintraub et al. 2011), including how these can be used to distinguish it from disorders that represent partial phenocopies. Next follows an article on the clues to causation and pathogenesis that arise from epidemiological studies of Alzheimer disease (Mayeux and Stern 2011). Then we embark upon an in-depth review of the latest ideas and findings on the biochemistry and molecular and cell biology of the processes that contribute to the development of the clinicopathological phenotype, including crucial insights that have arisen from human genetics (De Strooper et al. 2011; Goedert et al. 2011; Haass et al. 2011; Holtzman et al. 2011a; Ihara et al. 2011; LaFerla and Green 2011; Mandelkow and Mandeklow 2011; Masters and Selkoe 2011; Mucke and Selkoe 2011; Müller and Zheng 2011; Sagare et al. 2011; Saido and Leissring 2011; Tanzi 2011; Wyss-Coray and Rogers 2011). This detailed summary of the biology of the disorder represents the core of the collection. We conclude with three articles that discuss both existing treatments for $\mathrm{Alz}^{-}$ heimer disease and those that are currently in clinical trials or are expected to enter them before long (Aisen et al. 2011; Lee et al. 2011; Schenk et al. 2011). That therapeutic overview represents the promise of all of the multifaceted scientific efforts that the previous articles describe.

In the final article (Holtzman et al. 2011b), the editors of this collection speculate about how the expansive knowledge base may dramatically alter the way "Alzheimerology" is practiced within the next decade or two. We believe that the convergence of many scientific threads, particularly those from studies of fluid biomarkers and brain imaging, along with clinical genetics, should allow physicians to gauge risk with increasing accuracy and to monitor the development of the disease in its presymptomatic phase, before irreversible neuronal injury has occurred. The paradigm we describe emphasizes screening for the disorder in midlife (perhaps earlier) and then offering a range of preventions intended to stave off-or permanently avoid-progressive cognitive decline. Our projections disclose a strong sense of 
optimism that emerges from extraordinary progress in deciphering the biology of $\mathrm{Alz}$ heimer disease during our lifetimes.

\section{REFERENCES}

${ }^{*}$ Reference is also in this collection.

* Aisen PS, Cummings JL, Schneider LS. 2011. Symptomatic and non-amyloid/tau-based pharmacologic treatment for Alzheimer disease. Cold Spring Harb Perspect Med doi: $10.1101 /$ cshperspect.a006395.

Alzheimer A. 1907. Ueber eine eigenartige Erkrankung der Hirnrinde. Centralblatt fur Nervenheilkunde und Psychiatrie 30: $177-179$.

* Blennow K, Zetterberg H, Fagan AM. 2011. Fluid biomarkers in Alzheimer disease. Cold Spring Harb Perspect Med doi: 10.1101/cshperspect.a006221.

Blessed G, Tomlinson BE, Roth M. 1968. The association between quantitative measures of dementia and senile change in the cerebral grey matter of elderly subjects. Br J Psychiat 114: 797-811.

Brion J, Passareiro E, Nunez J, Flament-Durand J. 1985. Mise en evidence immunologique de la protein tau au niveau des lesions de degenerescence neurofibrillaire de la maladie D'Alzheimer. Arch Biol 95: 229-235.

* De Strooper B, Iwatsubo T, Wolfe MS. 2011. Presenilisn and $\gamma$-secretase: Structure, function, and role in Alzheimer disease. Cold Spring Harb Perspect Med doi: 10.1101/ cshperspect.a006304.

Glenner GG, Wong CW. 1984a. Alzheimer's disease and Down's syndrome: Sharing of a unique cerebrovascular amyloid fibril protein. Biochem Biophys Res Commun 122: $1131-1135$

Glenner GG, Wong CW. 1984b. Alzheimer's disease: Initial report of the purification and characterization of a novel cerebrovascular amyloid protein. Biochem Biophys Res Commun 120: 885-890.

Goate A, Chartier-Harlin M-C, Mullan M, Brown J, Crawford F, Fidani L, Giuffra L, Haynes A, Irving N, James L, et al. 1991. Segregation of a missense mutation in the amyloid precursor protein gene with familial Alzheimer's disease. Nature 349: 704-706.

* Goedert M, Ghetti B, Spillantini MG. 2011. Frontotemporal dementia: Implications for understanding Alzheimer disease. Cold Spring Harb Perspect Med doi: 10.1101/ cshperspect.a006254.

Grundke-Iqbal I, Iqbal K, Quinlan M, Tung Y-C, Zaidi MS, Wisniewski HM. 1986. Microtubule-associated protein tau: A component of Alzheimer paired helical filaments. J Biol Chem 261: 6084-6089.

* Haass C, Kaether C, Sisodia S, Thinakaran G. 2011. Trafficking and proteolytic processing of APP. Cold Spring Harb Perspect Med doi: 10.1101/cshperspect.a006270.

* Holtzman DM, Herz J, Bu G. 2011a. Apolipoprotein E and apolipoprotein E receptors: Normal biology and roles in Alzheimer disease. Cold Spring Harb Perspect Med doi: 10.1101/cshperspect.a006312.

* Holtzman DM, Mandelkow E, Selkoe DJ. 2011b. Alzheimer disease in 2020. Cold Spring Harb Perspect Med doi: 10.1101/cshperspect.a011585.
* Ihara Y, Morishima-Kawashima M, Nixon R. 2011. The ubiquitin-proteasome system and the autophagic-lysosomal system in Alzheimer disease. Cold Spring Harb Perspect Med doi: 10.1101/cshperspect.a006361.

* Johnson KA, Fox NC, Sperling RA, Klunk WE. 2011. Brain imaging in Alzheimer diseae. Cold Spring Harb Perspect Med doi: 10.1101/cshperspect.a006213.

Kang J, Lemaire H-G, Unterbeck A, Salbaum JM, Masters CL, Grzeschik K-H, Multhaup G, Beyreuther K, MullerHill B. 1987. The precursor of Alzheimer's disease amyloid A4 protein resembles a cell-surface receptor. Nature 325: 733-736.

Katzman R. 1976. Editorial: The prevalence and malignancy of Alzheimer disease. A major killer. Arch Neurol 33: 217-218.

Kidd M. 1964. Alzheimer's disease-An electron microscopical study. Brain 87: 307-320.

Kosik KS, Joachim CL, Selkoe DJ. 1986. Microtubule-associated protein, tau, is a major antigenic component of paired helical filaments in Alzheimer's disease. Proc Natl Acad Sci 83: 4044-4048.

* LaFerla F, Green KN. 2011. Animal models of Alzheimer disease. Cold Spring Harb Perspect Med doi: 10.1101/ cshperspect.a006320.

* Lee V, Brunden KR, Hutton M, Trojanowski JQ. 2011. Developing therapeutic approaches to tau, selected kinases, and related neuronal protein targets. Cold Spring Harb Perspect Med doi: 10.1101/cshperspect.a006437.

Levy E, Carman MD, Fernandez-Madrid IJ, Power MD, Lieberburg I, van Duinen SG, Bots GTAM, Luyendijk W, Frangione B. 1990. Mutation of the Alzheimer's disease amyloid gene in hereditary cerebral hemorrhage, Dutchtype. Science 248: 1124-1126.

* Mandelkow EM, Mandelkow E. 2011. Biochemistry and cell biology of tau protein in neurofibrillary degeneration. Cold Spring Harb Perspect Med doi: 10.1101/cshperspect.a006247.

* Masters CL, Selkoe DJ. 2011. Biochemistry of amyloid $\beta$-protein and amyloid deposits in Alzheimer disease. Cold Spring Harb Pespect Med doi: 10.1101/cshperspect.a006262.

* Mayeux R, Stern Y. 2011. Epidemiology of Alzheimer disease. Cold Spring Harb Perspect Med doi: 10.1101/cshperspect.a006239.

* Mucke L, Selkoe DJ. Neurotoxicity of amyloid $\beta$-protein: Synaptic networkdysfunction. Cold Spring Harb Perspect Med doi: 10.1101/cshperspect.a006338.

* Müller UC, Zheng H. 2011. Physiological functions of APP family proteins. Cold Spring Harb Perspect Med doi: 10.1101/cshperspect.a006288.

Nukina N, Ihara Y. 1986. One of the antigenic determinants of paired helical filaments is related to tau protein. J Biochem 99: 1541-1544.

* Sagare AP, Bell RD, Zlokovic BV. 2011. Neutovascular dysfunction and faulty amyloid $\beta$-peptide clearance in Alzheimer disease. Cold Spring Harb Perspect Med doi: 10.1101/cshperspect.a011452.

* Saido T, Leissring MA. 2011. Proteolytic degradation of amyloid $\beta$-protein. Cold Spring Harb Perspect Med doi: 10.1101/cshperspect.a006379. 
D. Selkoe et al.

* Schenk D, Basi GS, Pangalos MN. 2011. Treatment strategies targeting amyloid $\beta$-protein. Cold Spring Harb Perspect Med doi: 10.1101/cshperspect.a006387.

* Serrano-Pozo A, Frosch MP, Masliah E, Hyman BT. 2011. Neuropathological alterations in Alzheimer disease. Cold Spring Harb Perspect Med doi: 10.1101/cshperspect.a006189.

* Tanzi RE. 2011. The genetics of Alzheimer disease. Cold Spring Harb Perspect Med doi: 10.1101/cshperspect. a006296.

* Tarawneh R, Holtzman DM. 2011. The clinical problem of symptomatic Alzheimer disease and mild cognitive impairment. Cold Spring Harb Perspect Med doi: 10.1101/ cshperspect.a006148.
Terry RD. 1963. The fine structure of neurofibrillary tangles in Alzheimer's disease. J Neuropathol Exp Neurol 22: 629-642.

* Weintraub S, Wicklund AH, Salmon DP. 2011. The neuropsychological profile of Alzheimer disease. Cold Spring Harb Perspect Med doi: 10.1101/cshperspect.a006171.

Wood JG, Mirra SS, Pollock NL, Binder LI. 1986. Neurofibrillary tangles of Alzheimer's disease share antigenic determinants with the axonal microtubule-associated protein tau. Proc Natl Acad Sci 83: 4040-4043.

* Wyss-Coray T, Rogers J. 2011. Inflammation in Alzheimer disease- $\mathrm{A}$ brief review of the basic science and clinical literature. Cold Spring Harb Perspect Med doi: 10.1101/ cshperspect.a006346. 


\section{$\&_{\mathrm{CSH}}^{\infty} \&$ Cold Spring Harbor

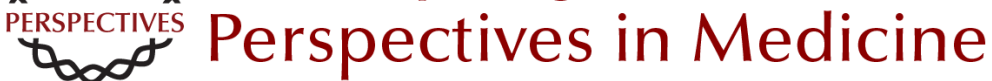

\section{Deciphering Alzheimer Disease}

Dennis Selkoe, Eckhard Mandelkow and David Holtzman

Cold Spring Harb Perspect Med 2012; doi: 10.1101/cshperspect.a011460 originally published online October 25, 2011

\section{Subject Collection The Biology of Alzheimer Disease}

Animal Models of Alzheimer Disease

Frank M. LaFerla and Kim N. Green

Neurovascular Dysfunction and Faulty Amyloid $\beta$

-Peptide Clearance in Alzheimer Disease Abhay P. Sagare, Robert D. Bell and Berislav V. Zlokovic

Treatment Strategies Targeting Amyloid $\beta$-Protein Dale Schenk, Guriqbal S. Basi and Menelas N. Pangalos

The Ubiquitin-Proteasome System and the Autophagic-Lysosomal System in Alzheimer Disease Yasuo Ihara, Maho Morishima-Kawashima and Ralph Nixon

Neurotoxicity of Amyloid $\beta$-Protein: Synaptic and Network Dysfunction Lennart Mucke and Dennis J. Selkoe

Proteolytic Degradation of Amyloid $\beta$-Protein Takaomi Saido and Malcolm A. Leissring

Brain Imaging in Alzheimer Disease Keith A. Johnson, Nick C. Fox, Reisa A. Sperling, et al.

Symptomatic and Nonamyloid/Tau Based Pharmacologic Treatment for Alzheimer Disease Paul S. Aisen, Jeffrey Cummings and Lon S. Schneider
Alzheimer Disease in 2020

David M. Holtzman, Eckhard Mandelkow and Dennis J. Selkoe

The Genetics of Alzheimer Disease Rudolph E. Tanzi

Fluid Biomarkers in Alzheimer Disease Kaj Blennow, Henrik Zetterberg and Anne M. Fagan

Epidemiology of Alzheimer Disease Richard Mayeux and Yaakov Stern

Biochemistry and Cell Biology of Tau Protein in Neurofibrillary Degeneration Eva-Maria Mandelkow and Eckhard Mandelkow

Biochemistry of Amyloid $\beta$-Protein and Amyloid Deposits in Alzheimer Disease Colin L. Masters and Dennis J. Selkoe

The Neuropsychological Profile of Alzheimer Disease

Sandra Weintraub, Alissa H. Wicklund and David P. Salmon

Apolipoprotein E and Apolipoprotein E Receptors: Normal Biology and Roles in Alzheimer Disease David M. Holtzman, Joachim Herz and Guojun Bu

For additional articles in this collection, see http://perspectivesinmedicine.cshlp.org/cgi/collection/ 